\title{
COMPRENDER EL PASADO PARA CONSTRUIR EL FUTURO. LA NECE- SIDAD DE UNA DIDÁCTICA DE LA ARQUEOLOGÍA PARA TODOS LOS PÚBLICOS
}

\author{
Gemma Cardona Gómez ${ }^{1}$
}

\section{Resumen:}

La didáctica de la arqueología es un campo que, aunque hace décadas que se desarrolla en nuestro país, presenta problemas de comprensión y conocimiento, en especial por el colectivo de arqueólogos y arqueólogas. Con tal de mejorar la relación entre arqueología y público desde la educación, es primordial dar a conocer la didáctica entre el colectivo de profesionales e investigadores de la arqueología, que comprendan qué implican los procesos de comunicación y educación en arqueología y patrimonio, para poder, junto con el público, construir un futuro para el campo del patrimonio arqueológico. Por ello, en el artículo se analizan las respuestas de los participantes al Cotarq sobre la definición y la finalidad de la didáctica (en o de) la arqueología, para relacionar sus visiones con el marco teórico que define la didáctica de la arqueología y, así, realizar una primera aproximación a las posibles divergencias en la visión de la educación patrimonial desde el mundo arqueológico.

\section{Palabras clave:}

didáctica, arqueología, educación, patrimonio, públicos

\begin{abstract}
:
Although archaeological education has been developed for some decades as a specific area of knowledge within archaeological science, there are still some problems in understanding what archaeological education is and what are their main aims, in particular among archaeologists. In order to improve the relationship between archaeology and the public from education, it is important to show archaeology professionals and researchers that archaeological education matters, and also to make them understanding the communication and education processes in order to build, with the public, a new future for archaeological dissemination and heritage protection. In this paper we are going to explore the conceptions related to archaeological education among participants in Cotarq conference. The definitions and ideas about the aims of archaeological education will be analyzed and explored, in order to link the conceptions of the participants to archaeological education theory to provide an exploratory approach on differences and similarities in archaeological education ideas both from theory and professionals.
\end{abstract}

1 Investigadora predoctoral del programa de Formación del Profesorado Universitario (FPU 2012) del Ministerio de Economía y Competitividad. Grupo de investigacion DIDPATRI - Didàctica del Patrimoni. Universitat de Barcelona 


\section{Key words:}

education, archaeology, teaching and learning, heritage, publics

\section{Qué es la didáctica de la arqueología, o por qué la ponencia se reconvirtió en pleno congreso}

Campus de Vicálvaro, 13 de noviembre de 2014. En pleno congreso del Cotarq, se desarrollaba la primera parte de la sesión de didáctica de la arqueología, con aportaciones de carácter diverso, presentadas por personas también diversas: estudiantes de grado, profesionales de la divulgación y la comunicación, profesionales del ámbito de la educación patrimonial. En el debate, alguien "abrió un melón" y surgieron preguntas y aspectos alrededor de la divulgación y la didáctica en el ámbito arqueológico, pero -desde mi perspectiva- con un denominador común: concepciones diversas y variadas sobre qué era la didáctica de la arqueología y cómo llevarla a cabo en ámbitos que abarcan desde los espacios virtuales, hasta las redes sociales y el contexto escolar. Sólo quedaban unas horas para presentar mi ponencia, que estaba enfocada a explicar la didáctica de la arqueología como estrategia educativa para todo tipo de públicos, a partir de una comprensión (es decir, más allá del mero conocimiento) del pasado para permitir que los públicos puedan construir futuro(s) en los ámbitos que consideren. Pero el debate del jueves por la tarde me hizo plantear un giro en la ponencia, enfocándola hacia una comprensión de la didáctica de la arqueología como ámbito y disciplina, ayudando a clarificar ideas y a plantear preguntas a un público al que no solemos dirigirnos: nuestros propios colegas del ámbito arqueológico. El objetivo principal era romper esquemas sobre la didáctica, explicar los componentes que la conforman y que permiten que el público pueda aprender, y presentar algunas problemáticas. Y, de esta forma, un título enfocado a presentar propuestas a arqueólogas y arqueólogos sobre cómo podían educar desde la arqueología a distintos públicos, se convertía en una oportunidad para intentar ofrecer un espacio de reflexión al colectivo profesional y en formación. Así, la "comprensión del pasado para construir el futuro" se convertía en la comprensión de "qué entendemos por didáctica de la arqueología" para poder construir este ámbito en el presente y el futuro. Así, la "didáctica para todos los públicos" acababa incluyendo, sin planificarlo anteriormente, al colectivo profesional del ámbito arqueológico.

En este artículo se expone una parte del contenido tratado en la ponencia presentada en el Cotarq. La estructura de la ponencia se componía de una primera parte de exploración de ideas previas de los asistentes y motivación de su reflexión alrededor de la didáctica de la arqueología, seguida por una segunda parte en que se definía el ámbito y se desglosaba en los distintos componentes de la acción didáctica: contenido, emisor o docente, público, contexto, estrategias, 
recursos y finalidad u objetivos. En este último punto también se tuvo en cuenta la participación del público asistente, y en todos los apartados se mostraban ejemplos y posibles preguntas para el debate, relacionadas con problemas actuales en el campo de la didáctica de la arqueología. Finalmente, las conclusiones se enfocaban hacia una visión de la didáctica como una forma de comunicar que, ante todo, necesita adaptarse a la realidad de la que parte y a la que se dirige. En este artículo nos centraremos principalmente en las dos cuestiones que se plantearon a los asistentes a la ponencia: ¿qué es la didáctica? ¿Por qué o para qué una didáctica de la arqueología? Se analizarán las respuestas recogidas el 14 de noviembre de 2014 al finalizar la sesión de didáctica y se compararán los resultados con las principales aportaciones teóricas del campo de la educación y la didáctica de la arqueología.

\section{Explorando las visiones de los asistentes al Cotarq sobre la didáctica de la arqueología: metodología}

Al repensar la ponencia para hacerla más adecuada y útil al público asistente al Cotarq en noviembre de 2014, uno de los objetivos que se plantearon pensando ya en la publicación del artículo era conocer cómo definía el público asistente la didáctica de la arqueología, y qué finalidad u objetivo creía que perseguía. Para ello, se recogieron las respuestas anónimas a las dos preguntas, formuladas en dos momentos de la ponencia. Antes de empezar la charla, se repartieron papeles en blanco a todos los asistentes (aproximadamente, a unas 60 personas). Al iniciar la ponencia, se explicó que se pediría la participación del público a lo largo de la exposición de distintas formas, y que esta participación anónima se incorporaría al artículo para las actas del congreso. Justo al inicio de la ponencia, se preguntó a los asistentes qué entendían por didáctica, y tuvieron un minuto para responder a la pregunta. La segunda pregunta, relativa a la finalidad u objetivos de la didáctica de la arqueología, se formuló casi al final de la ponencia, una vez ya se habían expuesto posibles definiciones de didáctica de la arqueología y se habían presentado los componentes de la acción didáctica y su aplicación en el ámbito arqueológico. En este caso, también se dejó un tiempo concreto al público asistente para responder. Al final de la sesión se recogieron las respuestas, y aunque la asistencia en la sala rondaba las 60 personas en el momento de exposición de la ponencia, al final se pudieron recoger 28 respuestas anónimas. Se debe tener en cuenta, por una parte, que algunos asistentes habían abandonado la sala antes de acabar la sesión, sin entregar sus respuestas; también el carácter voluntario y no controlado tanto de la respuesta a las preguntas como de su entrega al final de la sesión incidieron en el número de respuestas recopiladas. En cuanto a otros posibles sesgos en las respuestas recogidas, se encuentra el poco control del momento en que los asistentes escribieron sus respuestas, así como 
la posibilidad de que no fueran respuestas individuales, sino consensuadas con otros asistentes. Estos problemas podrían invalidar cualquier conclusión obtenida en otros ejemplos de investigación cualitativa, pero en nuestro caso se tendrán en cuenta como límite de generalización de las conclusiones. Se trata de una acción exploratoria, con finalidad reflexiva, sin ánimo de ofrecer una visión completa sobre qué concepciones tiene el colectivo de profesionales de la arqueología en España sobre su didáctica, y el análisis de las respuestas no pretende generalizar las conclusiones, sino ofrecer un espacio de reflexión al entorno de posibles interpretaciones y preconcepciones alrededor de la didáctica de la arqueología desde el mundo de la arqueología profesional y académica. A su vez, no se recogieron datos relativos a las características de cada uno de los participantes, por lo que no es posible distinguir las respuestas y los resultados en relación con estas características personales (sexo, edad, ocupación, etc).

Las respuestas, recogidas en formato manuscrito, se transcribieron en una tabla de datos y se han analizado desde una perspectiva cualitativa ${ }^{2}$ mediante el programa NVivo 10 para Windows. El análisis de las respuestas responde a una lógica propia del análisis temático del contenido 3 y la elaboración de los temas y los códigos ha seguido un proceso iterativo, combinando estrategias deductivas e inductivas. Esta estrategia de análisis cualitativo es útil para describir agrupaciones e interrelaciones de temas, y en nuestro caso puede ofrecer una descripción sobre las ideas que los asistentes al Cotarq tenían sobre la didáctica de la arqueología y su finalidad. Para el análisis, se han utilizado estrategias como el recuento de palabras, el análisis de relaciones entre códigos y referencias de codificación, y la agrupación de códigos para desvelar posibles modelos. En el proceso de codificación, se han podido identificar los siguientes temas (tabla 1).

\section{¿Qué es la didáctica de la arqueología? La visión de los participantes}

A la primera pregunta respondieron todos los participantes (28), aunque una de las respuestas se ha considerado nula por no ofrecer suficiente información para poder analizarla ${ }^{4}$. Si miramos la frecuencia de palabras (figura 1), la más presente

2 Siguiendo las líneas marcadas por M B. MILES y A. M. HUBERMAN: Qualitative Data Analysis: An Expanded Sourcebook. Sage, Thousand Oaks: 1994; y de J. W. CRESWELL: Research Design Qualitative, Quantitative and Mixed Methods Approaches. Sage, Thousand Oaks: 2003.

3 R. E. BOYATZIS: Transforming Qualitative Data: Thematic Analysis and Code Development. Sage, Thousand Oaks: 1998.

4 A la pregunta “¿Qué es la didáctica?", el o la participante respondió "Didáctica eres tú... ipor cómo has empezado!". Aunque del texto se deduce que algún elemento del inicio de la ponencia inspiró su respuesta, no sabemos del cierto qué fue, con lo que no podemos saber cómo define exactamente la didáctica. 
Acciones relacionadas con la didáctica Elementos de la acción didáctica

Didáctica como acción de enseñar

Didáctica como acción de enseñar y aprender

Didáctica como acción de hacer comprensible

Didáctica como acción de llegar al público

Didáctica como transmisión de conocimiento

Didáctica para producir emociones

Calificativos

Abstracto

Accesible

Alegre

Beneficios, utilidad

Claro

Comprensible

Efectivo

Interesante

Público y abierto

Rápido

Simple

Definición de didáctica

Didáctica como capacidad

Didáctica como disciplina

Didáctica como enseñanza

Didáctica como enseñanza y

aprendizaje

Didáctica como estrategia

Didáctica como proceso

Didáctica como técnica

Finalidad u objetivo

Adquirir conocimiento

Divulgación

Facilitar la comprensión

Finalidad de enseñar

Fomentar conocimiento

Fomentar el aprendizaje

Garantizar el conocimiento

Mejorar la cultura

Pasado-presente-futuro

Sensibilizar

Ser capaz de poner conocimientos en práctica

Transmitir conocimiento

Contenido

Algo, algún tema, alguna cosa

Arqueología

Arqueología como profesión

Arte

Ciencias o campos de estudio

Conocer el pasado

Conocimiento como contenido

Cultura universal

Historia

Objetos y restos patrimoniales

Patrimonio arqueológico

Contexto

Lugar (arqueológico)

Museo

Destinatario

A alguien

A todos los públicos

Público

Público visitante

Estrategias

Adaptación al contexto

Adaptación al público

Ameno

Atender a conocimientos previos

Atender al interés del visitante

Interacción

Interacción entre emisor y público

Participación

Provocar la curiosidad

Recursos

Respuesta no válida
Tabla1. Temas y códigos identificados en el proceso de análisis de las respuestas de los participantes. 
en el texto es "conocimiento" (13 veces), junto con "didáctica" (8), "enseñar" (8), "forma" (8), "enseñanza" (5), "arte" (4) y "transmitir" (4). La palabra "didáctica" tiene una alta presencia a consecuencia de responder la primera pregunta parafraseando el concepto ${ }^{5}$. Si agrupamos los conceptos anteriores con palabras similares o derivadas de ellos, obtendríamos una mayor representatividad de los temas que evocan en las respuestas. Así, "enseñar" (8 veces) se puede agrupar con "enseñanza" (5) y "enseñado" (1), resultando en una frecuencia del concepto relativo al acto de "enseñar" de 14 veces, superando la frecuencia de "conocimiento". A su vez, "transmitir" (4) se puede asociar a "transmisión" (3), resultando una frecuencia de 7 veces. Al agruparlos, otras palabras como "público" (3) o "personas" (3) adquieren importancia, al referirse a los destinatarios de la acción didáctica, de la misma forma que "aprendizaje" (2) y "aprender" (2). En el caso de la palabra "arte", en dos ocasiones se utiliza para definir la didáctica, y en otros dos, para nombrar la disciplina artística como contenido de la didáctica en el campo de la arqueología6. Es importante señalar la repetición de la palabra "forma", que se puede asociar a las palabras "modo" (2) y "manera" (2), y se refieren tanto a cómo definieron los participantes la didáctica (por ejemplo, "La didáctica es la forma de enseñar algo a una persona", ID 16, respuesta 1), pero también cómo concretaron esta definición (como en el caso "Enseñanza de un tema de forma amena" ID 10, respuesta 1). En el caso de la palabra "conocimiento", si analizamos con qué otras palabras se asocia (figura 2), podemos observar que, en general, se relaciona con palabras y conceptos como "transmitir" y "transmisión", es decir, a acciones vinculadas a la comunicación, la difusión, de conocimiento, y a garantizarlo, promoverlo, fomentarlo. En el caso de la palabra "enseñar" y similares ("enseñanza", "enseñado") (figura 3), sirven para definir la didáctica, pero también se asocian a la acción de "enseñar a aprender" y al concepto de transmitir, comunicar algún tipo de contenido a alguien.

En la codificación de las respuestas a la primera pregunta, los temas más recurrentes han sido relativos a las acciones vinculadas a la didáctica, como la "Didáctica como transmisión de conocimiento" (11 veces) y la "Didáctica como acción de enseñar" (10 veces), pero también en las definiciones de didáctica ("didáctica como técnica", 10 veces, "didáctica como enseñanza" 5 veces, "didáctica como proceso", 5 veces), en el campo del destinatario de la acción didáctica ("a alguien", 8 veces) y también el campo del contenido didáctico ("algún tema", 5 veces). La frecuencia de estos códigos, en parte, se corresponde con la frecuencia de conceptos vinculados, de los que hemos hablado más arriba. Por otra parte, y centrándonos en los temas relacionados directamente con las definiciones de di-

5 Por ejemplo, "La didáctica es una herramienta abstracta para fomentar y desarrollar el aprendizaje" (ID7, respuesta 1).

6 Como ejemplos, "La didáctica es el arte de enseñar a los demás" (ID 8, respuesta 1); "Didáctica es la forma de hacer comprensible y entendible aquellos aspectos de distintas ciencias o campos de estudio: arte, biología, etc." (ID 13, respuesta 1). 
dáctica que han aportado los participantes, podemos observar algunas tendencias cuando observamos la concurrencia de codificación entre los temas vinculados a los términos usados para definir didáctica, y las acciones que, según las respuestas de los participantes, realiza la didáctica (tabla 2).

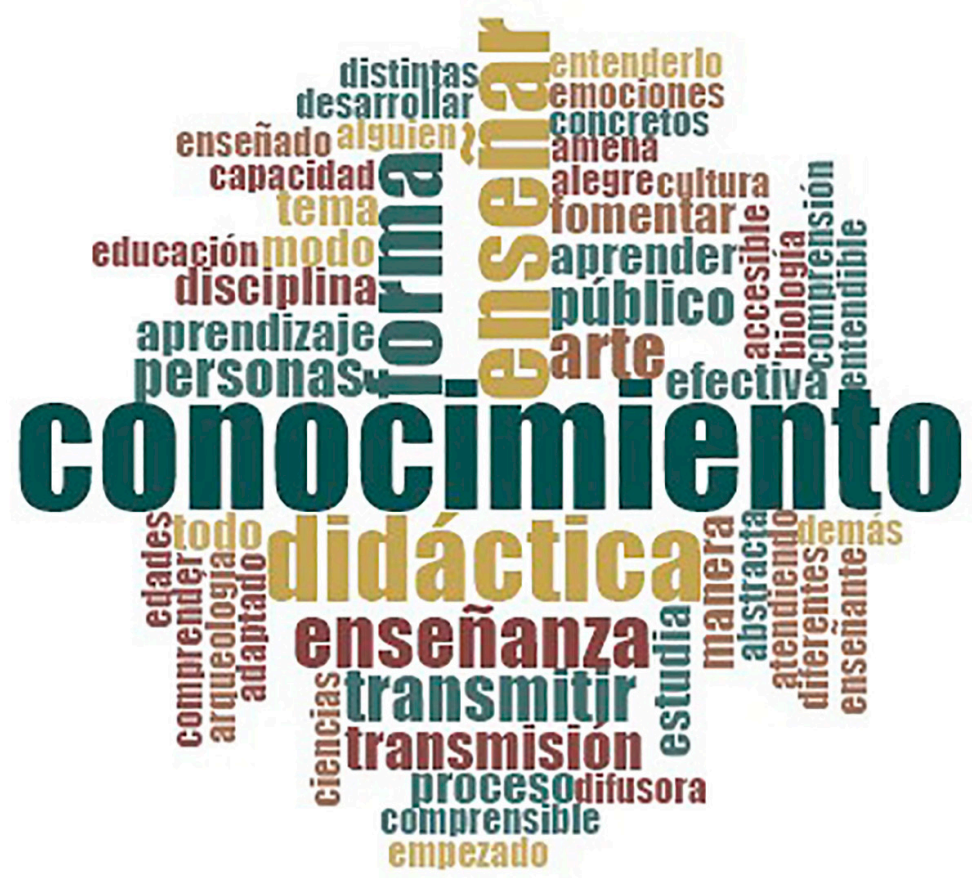

Figura 1. Nube de palabras correspondiente al recuento de frecuencia de palabras para las respuestas a la pregunta 1 .

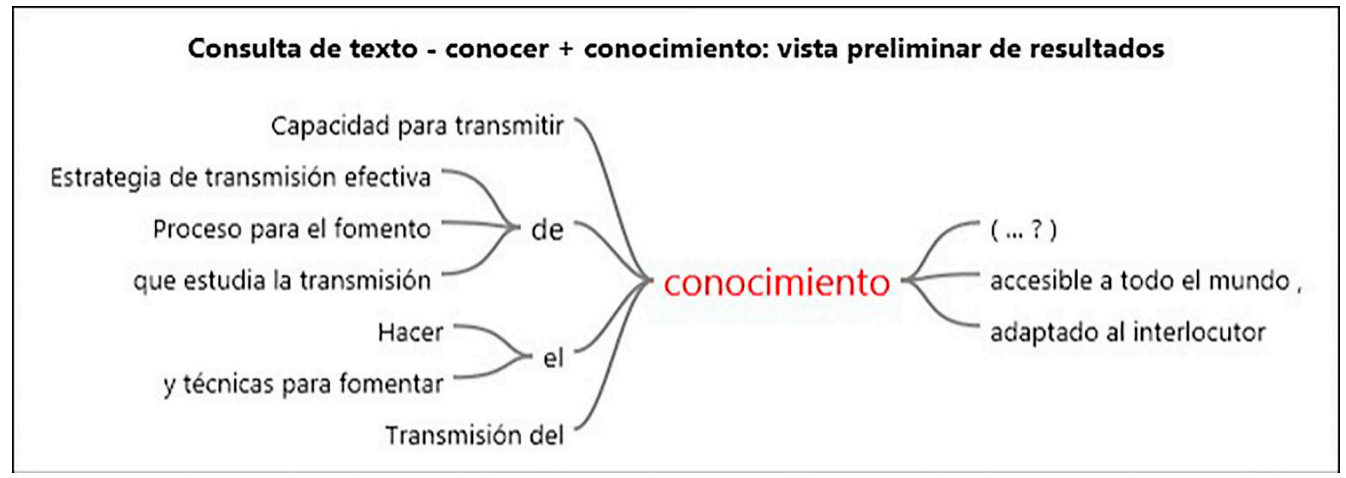

Figura 2. Árbol de palabras relacionado con "conocimiento" en las respuestas de la pregunta 1. 


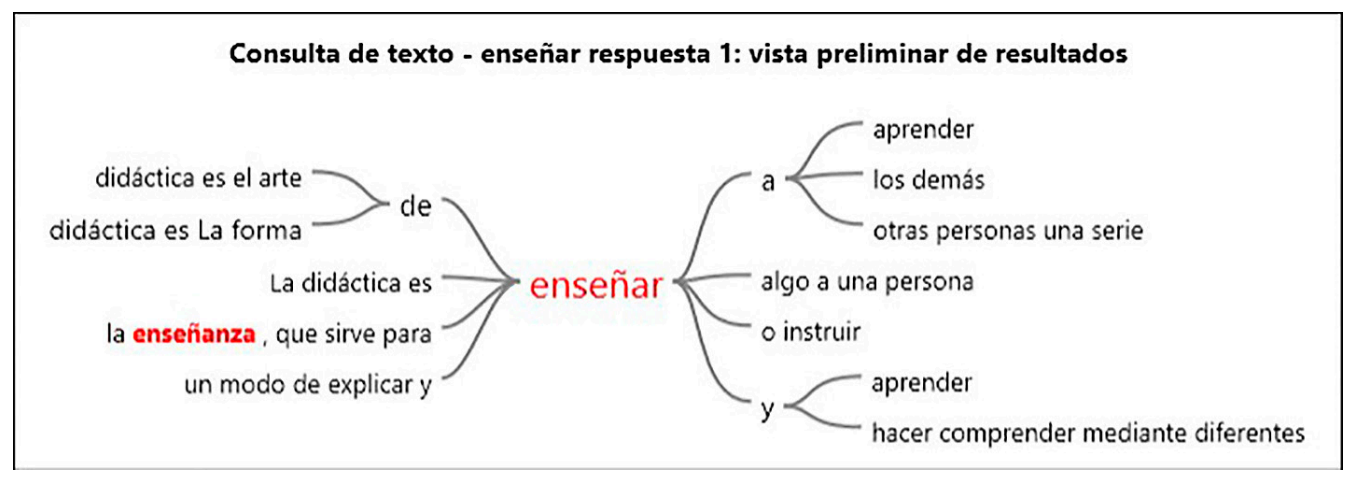

Figura 3. Árbol de palabras relacionado con "enseñar" y "enseñanza" en las respuestas de la pregunta 1.

\begin{tabular}{|c|c|c|c|c|c|c|c|}
\hline A: Acciones relacionadas con la didáctica & 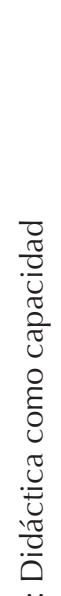 & 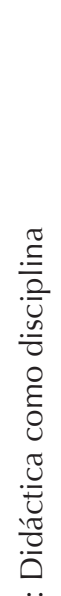 & 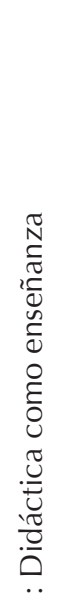 & 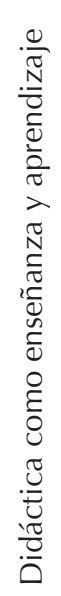 & 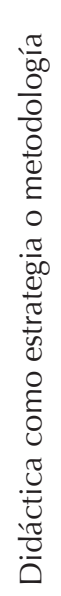 & 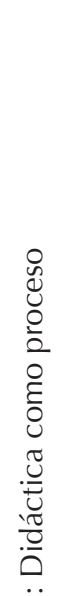 & 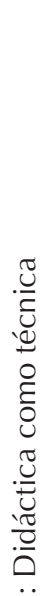 \\
\hline 1: Definición de didáctica & $\ddot{\infty}$ & $\dot{u}$ & 0 & $\ddot{山}$ & $\ddot{\leftarrow}$ & $\circlearrowleft$ & I \\
\hline 2 : Didáctica como acción de enseñar & & & 5 & & & 1 & 4 \\
\hline 3 : Didáctica como acción de enseñar y aprender & & 1 & & 1 & & & 1 \\
\hline 4 : Didáctica como acción de hacer comprensible & & & 1 & & & & 1 \\
\hline 5 : Didáctica como acción de llegar al público & & & & & & & 1 \\
\hline 6: Didáctica como acción para el aprendizaje & & & & & & & 2 \\
\hline 7 : Didáctica como museografía o museología & & & & & & & 1 \\
\hline 8 : Didáctica como transmisión de conocimiento & 3 & 1 & & & 2 & 4 & 1 \\
\hline 9 : Didáctica para producir emociones & & & & & & 1 & \\
\hline
\end{tabular}

Tabla 2. Matriz de codificación en las respuestas a la primera pregunta, entre los códigos del tema "Definición de didáctica" y "Acciones vinculadas a la didáctica". 
Siguiendo la tendencia observada en la frecuencia de palabras y la frecuencia de codificación, observamos cómo, en las definiciones de "didáctica" aportadas por los asistentes a la ponencia, las visiones más recurrentes se relacionan con una didáctica definida como enseñanza ( 5 casos) y entendida como técnica, modo o forma de enseñar (4 casos). Por otra parte, un total de 11 personas relacionan la didáctica con la acción de transmitir conocimiento, definiéndola como el proceso de transmisión (4 personas), la capacidad para transmitir este conocimiento (3 casos), como estrategia o metodología para realizar esta transmisión ( 2 casos), o bien como forma ( 1 persona) o disciplina ( 1 persona) para transmitir conocimiento. Aunque parezcan similares, el hecho de definir la didáctica como "capacidad" implica que es inherente a la persona que ejerce la didáctica, que es una habilidad que puede aprenderse; mientras que, definiendo la didáctica como proceso o acción de transmisión de conocimiento, esta perspectiva no se muestra. Es destacable señalar que sólo dos personas definieron la didáctica como disciplina (una en relación con la transmisión de conocimiento, otra en relación a enseñar y aprender). A su vez, otros participantes (un total de 11) han relacionado la didáctica como técnica, forma o modo de realizar alguna acción relacionada con la comunicación: como modo de desarrollo o fomento del aprendizaje (2 casos), como técnica de enseñanza (4 personas), o bien para hacer comprensible, enseñar y aprender, y también para hacer llegar algún mensaje al público (1 caso en cada uno).

Destacar que sólo una persona ha relacionado la didáctica con la acción de emocionar ${ }^{7}$, mientras que dos personas la han vinculado a la acción de hacer comprensible ${ }^{8}$. Aunque estas dos definiciones parezcan similares a las relacionadas con "enseñar", muestran unos matices que no podemos concretar sólo con las palabras "enseñanza" o "enseñar". En el caso de la producción de emociones, implica que, según esa persona, la didáctica va más allá de comunicación para poder emocionar; aunque debemos tener en cuenta que, debido a la escueta respuesta, no podemos concretar cómo esta definición se relaciona con otras concepciones más relacionadas con la enseñanza o la transmisión de conocimientos. En el caso de las personas que definieron la didáctica como comprensión, significa que han tenido en cuenta la perspectiva del destinatario, y que consideran que la didáctica debe buscar, más allá de conocer y aprender, el hecho de comprender.

El análisis de las definiciones y las acciones vinculadas a la didáctica por los participantes nos ha llevado a definir distintos enfoques hacia la definición de

7 ID14, respuesta 1: "Producir emociones".

8 ID13, respuesta 1: "Didáctica es la forma de hacer comprensible y entendible aquellos aspectos de distintas ciencias o campos de estudio: arte, biología, etc."; ID17, respuesta 1: "La didáctica es enseñar y hacer comprender mediante diferentes métodos algo sobre lo que sabemos a otras personas para ponerlas en práctica". 
didáctica, y también a definir perspectivas distintas según si la definición se centraba en la acción a desarrollar por el emisor, por el destinatario, o por ambos (mixto). En base a las definiciones y las acciones, hemos podido definir 6 enfoques diferentes: enfoque aprendizaje, enfoque comprensivo, enfoque educativo, enfoque emocional, enfoque enseñanza y enfoque transmisivo. Cada uno de ellos se corresponde con una forma de definir la didáctica y las acciones que se vinculan a ella, y podemos clasificarlas en un gradiente relacionado, por una parte, con la perspectiva (desde el emisor al receptor, o mixto) y, por otra parte, en relación a una visión más comunicativa, transmisiva, con finalidad de difusión, que genera una progresión hacia una acción más participativa desde una perspectiva educativa. En la discusión de resultados, más adelante, relacionaremos estos enfoques con modelos teóricos derivados de la comunicación patrimonial, la participación pública, la arqueología pública y comunitaria, y la didáctica de la arqueología.

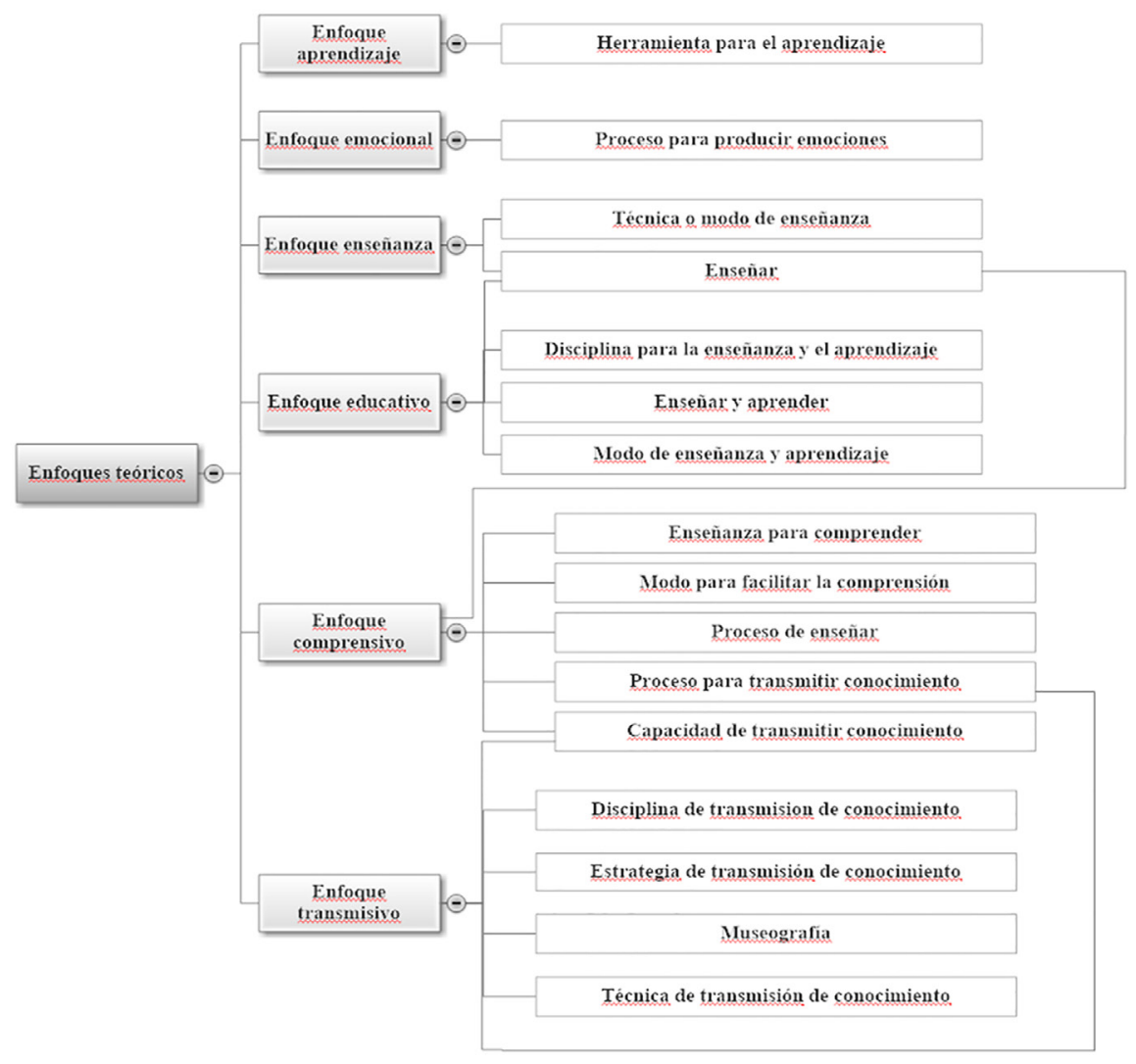

Figura 4. Correspondencia entre enfoques teóricos para describir la didáctica y definiciones aportadas por los participantes. 
Estos enfoques se han concretado a partir de las diferentes definiciones de didáctica según los participantes (figura 4). El enfoque aprendizaje se ha definido a partir de aquellas aportaciones que relacionaban de forma explícita y directa la didáctica con el aprendizaje del destinatario ${ }^{9}$. Aunque a priori este enfoque podría incluirse en la perspectiva del destinatario, hemos considerado que es mixto porque, en la respuesta, el o la participante describió la didáctica para "fomentar y desarrollar el aprendizaje" (ver nota 9). La acción de fomentar la realiza el emisor, mientras que la acción de desarrollar el aprendizaje es propia del receptor: por esto lo hemos considerado como enfoque mixto. El enfoque emocional está representado por la única definición relacionada con la producción de emociones (véase nota 7); se ha considerado importante separarla de los otros enfoques porque aporta una visión distinta al aprendizaje, la enseñanza o la transmisión de conocimientos.

Por su parte, el enfoque enseñanza se concreta con las definiciones que señalan a la didáctica como enseñanza en si misma (3 casos) y también con la técnica o el modo de enseñar (4 casos). Este enfoque se diferencia del enfoque educativo en que los y las participantes no nombraron en ningún momento la acción de enseñanza vinculada al aprendizaje, sino solo como instrucción o enseñanza. Por lo tanto, se trata de un enfoque encarado desde la perspectiva del emisor. El enfoque educativo, precisamente, también contiene un caso en el que la didáctica se definió como enseñanza, pero que incluía la perspectiva del aprendizaje ${ }^{10}$. Este enfoque está también formado por aquéllas definiciones de didáctica como disciplina de enseñanza y aprendizaje ${ }^{11}$; cómo enseñanza para enseñar y aprender ${ }^{12}$; o bien como modo de enseñanza y aprendizaje ${ }^{13}$. Algunas de las definiciones vinculadas al enfoque educativo mostrarían una perspectiva desde el emisor (ver notas 10 y 11 ), mientras que otras se relacionan con el emisor y el receptor desde una perspectiva mixta (ver notas 12 y 13 ).

A partir de las definiciones se ha podido concretar también un enfoque comprensivo que, más allá de provocar o fomentar un aprendizaje o un conocimiento en el destinatario, pretende que éste comprenda, entienda y, por lo tanto, que adquiera un conocimiento más profundo de aquello que queramos comunicar. Está relacionado también con la definición de didáctica como enseñanza ${ }^{14}$, así como

9 ID7, respuesta 1: "La didáctica es una herramienta abstracta para fomentar y desarrollar el aprendizaje".

10 ID 24, respuesta 1: "Enseñar a aprender".

11 ID 26, respuesta 1: "Disciplina que estudia los procesos utilizados en la educación".

12 ID 25, respuesta 1: "Enseñar y aprender".

13 ID 6, respuesta 1: “Un modo de aprendizaje y enseñanza, de manera que interactúen enseñante y enseñado".

14 ID 17, respuesta 1: "La didáctica es enseñar y hacer comprender mediante diferentes métodos algo sobre lo que sabemos a otras personas para ponerlas en práctica". 
con la didáctica como enseñar y hacer comprender ${ }^{15}$, con el modo para facilitar la comprensión ${ }^{16}$, con el proceso de enseñanza ${ }^{17}$, la capacidad de transmitir conocimiento ${ }^{18}$ y también con el proceso de transmisión de conocimiento ${ }^{19}$. El enfoque comprensivo se vincula al emisor, pues, aunque la acción de comprender la realiza el destinatario, todas las definiciones relacionadas con la comprensión explicitan sólo la acción de "fomentar" o "facilitar" esta comprensión; acciones llevadas a cabo por el emisor.

Finalmente, el enfoque transmisivo se relaciona con aquellas definiciones que conciben la didáctica como acción de transmisión del conocimiento, entendiendo transmisión como comunicación, difusión, divulgación. Por ello, además de vincularse a las definiciones de didáctica como $\operatorname{procesO}^{20}$ y capacidad $^{21}$ de transmisión de conocimiento, también está relacionada con aquéllas que la definen como disciplina ${ }^{22}$, estrategia ${ }^{23}$ o técnica ${ }^{24}$ de transmisión de este conocimiento, además de la concepción de didáctica relacionada con museografía ${ }^{25}$. El enfoque transmisivo se vincula a la perspectiva del emisor, puesto que, aunque la transmisión se dirige a alguien, es el emisor quien efectúa la acción.

\section{¿Cuál es el objetivo o finalidad de la didáctica de la arqueología?}

Siguiendo las técnicas de análisis que hemos aplicado a las respuestas a la primera pregunta, analizaremos las respuestas a la pregunta relativa al objetivo o finalidad de la didáctica de la arqueología. Antes de analizar las respuestas, debemos tener en cuenta que en tres casos los participantes no contestaron a la segunda pregunta formulada. De estos 3 casos, en uno de ellos respondía a la fi-

15 ID 17, respuesta 1: "La didáctica es enseñar y hacer comprender mediante diferentes métodos algo sobre lo que sabemos a otras personas para ponerlas en práctica".

16 ID 13, respuesta 1: "Didáctica es la forma de hacer comprensible y entendible aquellos aspectos de distintas ciencias o campos de estudio: arte, biología, etc".

17 ID 12, respuesta 1: "Hacer el conocimiento accesible a todo el mundo, mediante una enseñanza dirigida a su comprensión".

18 ID 22, respuesta 1: "La didáctica es saber transmitir los conocimientos de una forma en la que puedan entenderlo el público al que va dirigida, de una forma interesante y difusora".

19 Ver nota 17.

20 Como ejemplo, ID 5, respuesta 1: "Hacer llegar conocimientos de Historia, Arqueología,

Arte... cultura a todos los públicos, atendiendo a los conocimientos previos y a las edades".

21 Como ejemplo, ID 4, respuesta 1: "Capacidad para transmitir conocimiento".

22 ID 21, respuesta 1: "Disciplina que estudia la transmisión de conocimiento".

23 ID1, respuesta 1: "Estrategia de transmisión efectiva de conocimiento".

24 ID3, respuesta 1: "Medios y técnicas para fomentar el conocimiento".

25 ID 11, respuesta 1: "La forma en cómo los materiales u objetos que se presentan en un museo llegan al público". 
nalidad de la didáctica de la arqueología con la respuesta a la primera pregunta ${ }^{26}$. Esto debe tenerse en cuenta, pues implica que, por alguna razón, tres personas no contestaron a una de las dos preguntas.

Ahora sí, entrando en el análisis, si tenemos en cuenta la frecuencia en que algunas palabras se repiten en el texto, podemos observar tendencias similares a las que ya hemos descrito relativas a la respuesta 1. En las segundas respuestas, las palabras más frecuentes son "conocimiento" (9 veces), "enseñar" (9 veces), "arqueología" (7 casos), "pasado" (6 casos), "conocer" (5 veces) y "forma" (5 casos) (figura 5). Si relacionamos estos conceptos con otras palabras vinculadas, podemos observar como "conocimiento" es similar a "conocer", y sumadas están presentes 14 veces en el texto. Lo mismo pasaría con "arqueología" (7) y "arqueológico" (3), que sumarían 10 veces, y "enseñar" (9) y "enseñanza" (1) que también estarían presentes 10 veces. En línea con lo que se podía observar en las respuestas a la primera pregunta, las palabras más frecuentes se relacionan con conocer, saber, conocimiento, así como la enseñanza. Esta vez también tiene importancia la palabra "arqueología" y similares, así como "pasado", porque en muchas de las respuestas se concreta la finalidad de la didáctica al campo concreto del conocimiento del pasado y la arqueología. Si analizamos las palabras con las que están relacionadas "conocimiento" y "enseñanza", podemos observar cómo, en el primer caso, conocimiento se vincula con acciones (y finalidades) vinculadas a la transmisión, adquisición o difusión de conocimiento, que muchas veces se vincula al público como destinatario de esta transmisión, pero también con un tipo de conocimiento relacionado con la arqueología y la historia (figura 6). En el caso de "enseñar" (figura 7), define la acción principal de la didáctica y su finalidad para muchos participantes, y se vincula también a enseñar contenidos propios del conocimiento arqueológico e histórico, pero también a cómo enseñar: de forma amena, eficaz, que sea comprensible.

En cuanto a los temas y códigos más frecuentes localizados en las respuestas a la segunda pregunta, se refieren a la finalidad de la didáctica (39 referencias de codificación), a elementos de la acción didáctica (35 referencias) y calificativos relacionados con distintos elementos (11 referencias). Un análisis más detallado nos da cuenta que las finalidades con más referencias de codificación son las relativas a la enseñanza (10 referencias) y el fomento del conocimiento (8 referencias), seguidos del objetivo de facilitar la comprensión (5 referencias). En cuanto a los elementos de la acción didáctica, los más nombrados en las respuestas a la segunda pregunta se refieren al contenido (18 referencias), en especial a la arqueología (6), conocer el pasado (4) y a la historia como contenido a transmitir (4), pero también están muy presente aspectos relacionados con los destinatarios (9 referencias).

26 ID 17, respuesta 1: "La didáctica es enseñar y hacer comprender mediante diferentes métodos algo sobre lo que sabemos a otras personas para ponerlas en práctica". 


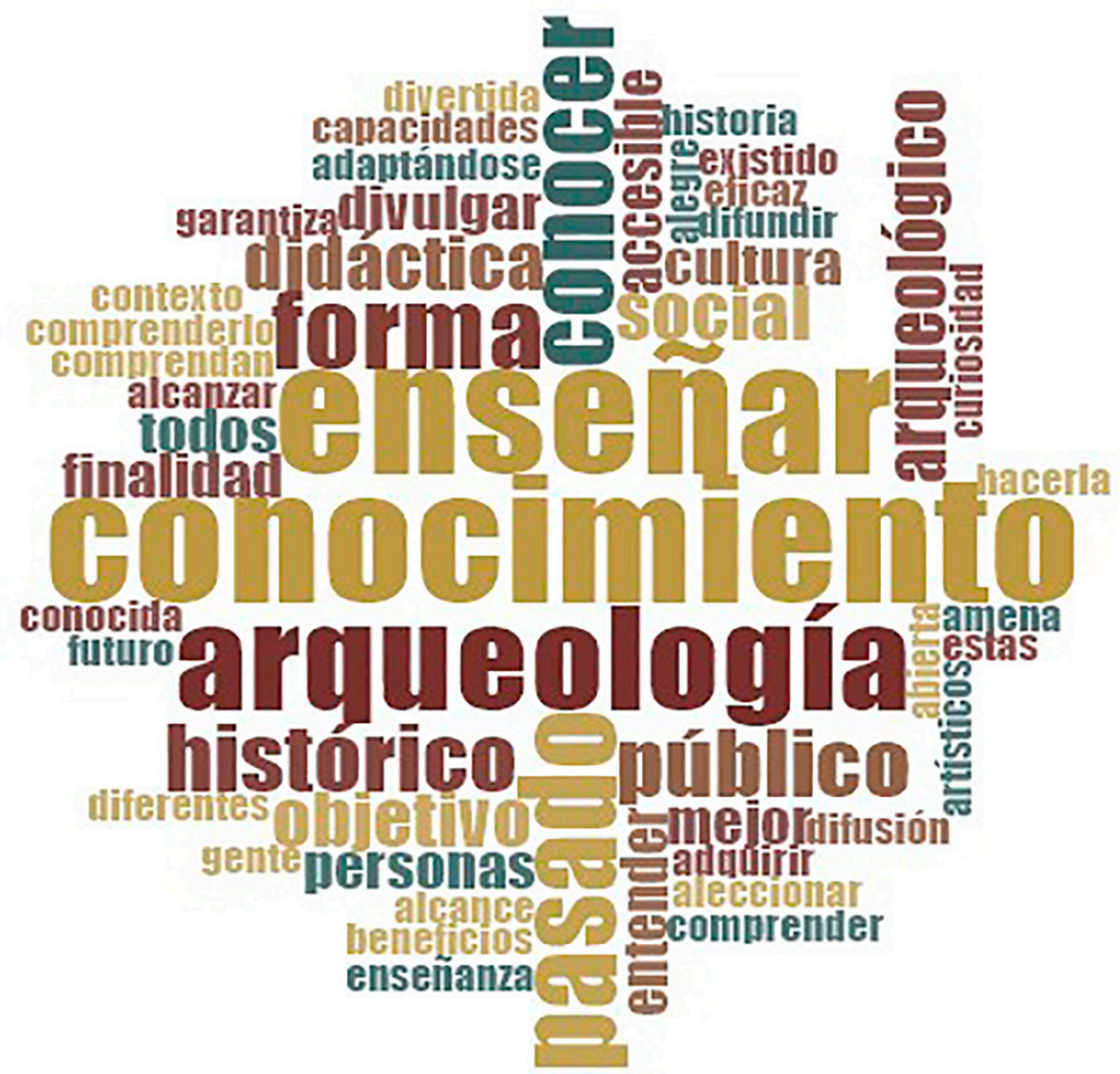

Figura 5. Nube de palabras con la frecuencia con la que aparecen los conceptos en el texto de las respuestas a la segunda pregunta.

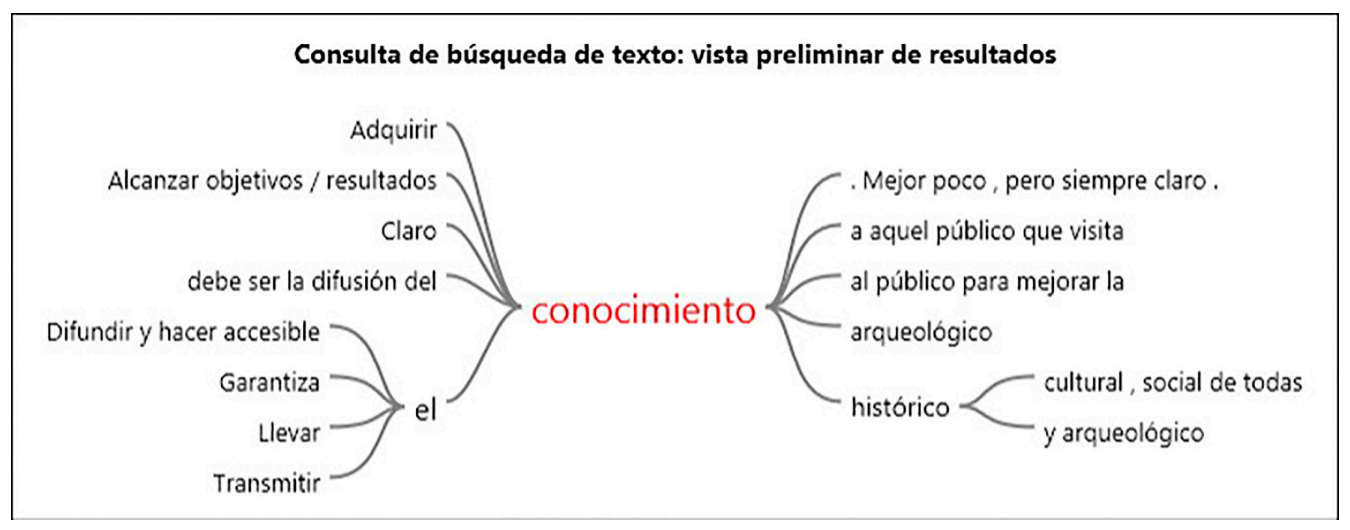

Figura 6. Árbol de palabras relacionadas con el concepto "conocimiento" en las respuestas a la segunda pregunta. 


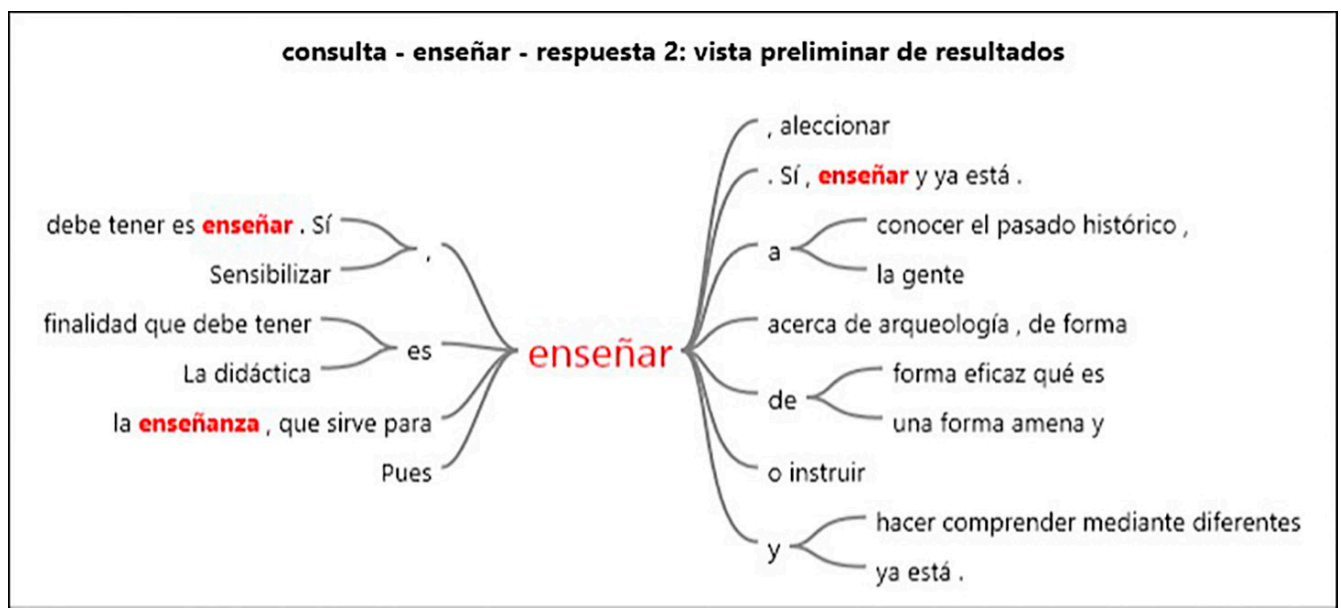

Figura 7. Árbol de palabras relacionadas con el concepto "enseñar" en las respuestas a la segunda pregunta.

A lo largo del proceso de codificación temática se han podido relacionar y asociar los temas relativos a la finalidad u objetivo de la didáctica (de o en la arqueología) con otros temas y códigos (figura 8). Observando el modelo resultante, podemos ver cómo algunas finalidades se relacionan, en ocasiones, entre ellas, pues algunos participantes las nombran juntas, o bien su significado está asociado. En el primer caso tendríamos como ejemplo la transmisión de conocimiento para mejorar la cultura (ID 25, respuesta 2: "Llevar el conocimiento al público para mejorar la cultura"), y también los casos de relación entre la función pasado-presente-futuro, que se vincula a la preservación y conservación (para un futuro), al fomento del conocimiento (del pasado) y a la comprensión (del presente $)^{27}$. Como ejemplos de significado asociado entre finalidades, encontramos la asociación o la equivalencia entre divulgación y transmisión de conocimiento: "El objetivo de la didáctica de la arqueología es divulgar de forma pública y abierta para conocer el pasado" (ID 21, respuesta 2). Si nos fijamos en las finalidades más citadas (enseñar y fomentar el conocimiento), podemos ver cómo, en ocasiones, se encuentran relacionadas (ID 7, respuesta 2: "Pues, en mi opinión, el objetivo debe tener unas bases para poder llevar a cabo el método de enseñanza y poner unos conocimientos históricos y artísticos sobre el tema que se trate."). Si las analizamos por separado, podemos ver cómo la finalidad de fomentar el conocimiento se vincula, en ocasiones, a fomentar un mejor conocimiento de la arqueología como profesión ${ }^{28}$, o bien a fomentar un conocimiento claro ${ }^{29}$. En el

27 ID 3, respuesta 2: "Conocer el pasado, entender el presente y preservar en el futuro".

28 ID 23, respuesta 2: "La arqueología no solo es una profesión sino un oficio, y por lo tanto, debería ser conocida".

29 ID 10, respuesta 2: "Claro conocimiento. Mejor poco, pero siempre claro". 
caso del objetivo de enseñar, se relaciona con enseñar de forma amena ${ }^{30}$, efecti$v^{31}$, al público ${ }^{32}$, y mediante estrategias participativas ${ }^{33}$.

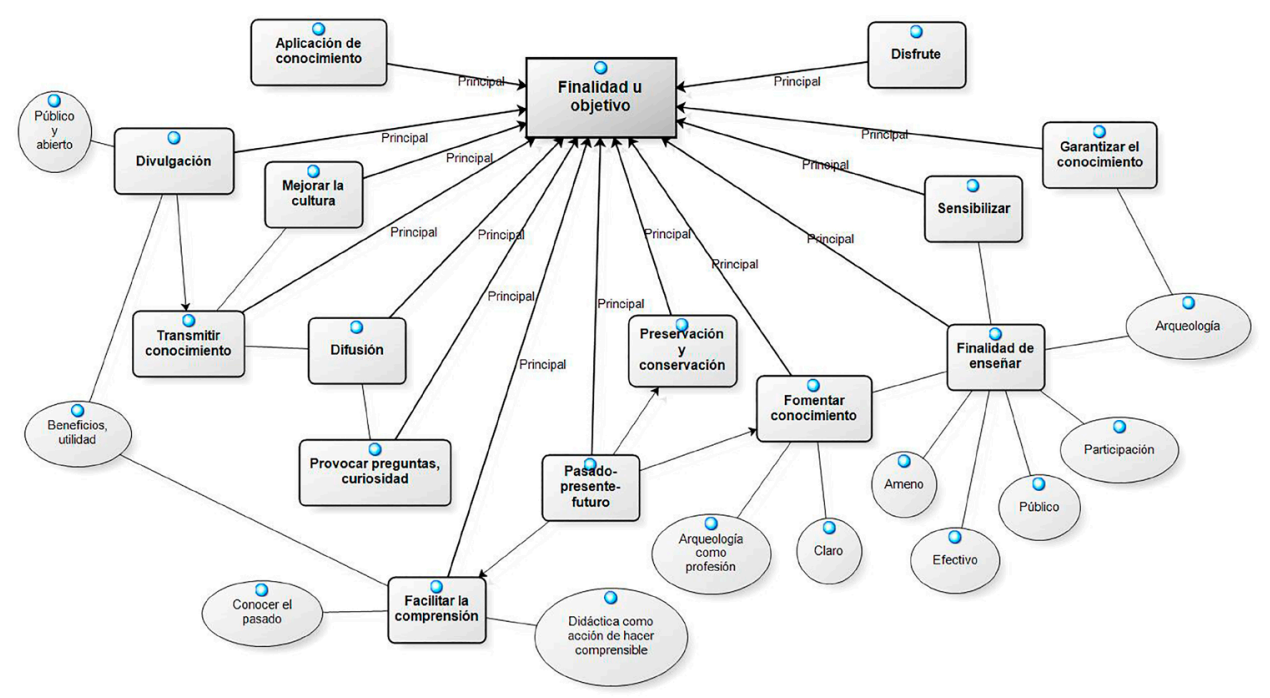

Figura 8. Modelo que muestra las relaciones entre los temas que describen la finalidad u objetivo de la didáctica con otros elementos temáticos.

Si tenemos en cuenta las relaciones anteriores y sus posibles agrupaciones, podríamos establecer diferentes finalidades de tipo teórico o interpretativo. Para realizarlo, hemos agrupado los temas relativos a la finalidad de la didáctica según el tipo de acción que desarrollan, hacia quién se dirige y qué espera del receptor con su acción. Mediante este proceso, se han podido distinguir las siguientes finalidades teóricas:

- Transmitir y difundir el conocimiento: se compone de aquellas visiones que vinculan la didáctica con la finalidad de difundir, divulgar o transmitir conocimiento a un público amplio. Un total de 7 referencias se vinculan a esta visión ${ }^{34}$. Las respuestas apuntan a una perspectiva desde el emisor.

- Enseñar: la finalidad de enseñar se compone de aquellas respuestas relacionadas con la enseñanza como finalidad ${ }^{35}$. Un total de 9 referencias se

30 ID 6, respuesta 2: "Enseñar de una forma amena y participativa".

31 ID 14, respuesta 2: "Enseñar de forma eficaz qué es la arqueología".

32 ID 19, respuesta 2: "Enseñar a la gente".

33 Ver nota 30.

34 Como ejemplo, ID 11, respuesta 2: "Transmitir el conocimiento a aquel público que visita el lugar". 35 Como ejemplo, ID 2, respuesta 2: "Pues enseñar acerca de arqueología, de forma rápida y alegre". 
relacionan con esta concepción del objetivo final de la didáctica, centradas en una perspectiva propia del emisor.

- Disfrute y diversión: la finalidad de la didáctica de la arqueología es, también, producir placer, divertir, entretener. Así lo expresa uno de los participantes: "Hacerla divertida y accesible a todos los públicos" (ID 15, respuesta 2). Esta visión tiene en cuenta tanto al emisor como al receptor, y, por lo tanto, se podría considerar como una finalidad de una perspectiva mixta.

- Aprendizaje y fomento del conocimiento: según esta visión, la finalidad de la didáctica está directamente vinculada al aprendizaje y el fomento del conocimiento. Por ello, esta categoría interpretativa incluye los temas sobre la finalidad de garantizar y fomentar el conocimiento ${ }^{36}$, así como mejorar la cultura del público destinatario. Es una categoría vinculada a una perspectiva mixta, que tiene en cuenta al emisor y al receptor. Un total de 11 referencias están relacionadas con esta finalidad.

- Facilitar la comprensión: más allá de provocar un aprendizaje o fomentar un conocimiento de algún tema en concreto, algunos participantes expresaron que la finalidad de la didáctica era hacer comprender, entender ${ }^{37}$. Esta finalidad está presente en 5 referencias, y se vincula a una perspectiva desde emisor y receptor.

- Provocar preguntas: alguno de los participantes expresó que la finalidad de la didáctica era, además de difundir un conocimiento, que esta acción comunicativa despertara el interés del destinatario y le provocara pregun$\operatorname{tas}^{38}$. Esta finalidad también se vincularía a una perspectiva mixta.

- Saber aplicar el conocimiento: uno de los participantes expresó que la didáctica debía tener como finalidad, entre otras, que el destinatario fuera capaz de poner en práctica los conocimientos adquiridos ${ }^{39}$. Esta finalidad también expresa una perspectiva mixta entre emisor y receptor.

- Sensibilización y protección: otros participantes relacionaron la finalidad de la didáctica con promover la preservación y conservación del patrimonio, y sensibilizar al público ${ }^{40}$. Se trata también de una perspectiva mixta.

36 Como ejemplo, ID 28, respuesta 2: "Alcanzar objetivos/resultados conocimiento".

37 Como ejemplo, en la ID 9, respuesta 2: "Enseñar a conocer el pasado histórico, cultural... al resto del mundo para conocer mejor el pasado y comprenderlo".

38 ID 22, respuesta 2: "Su finalidad debe ser la difusión del conocimiento histórico cultural, social de todas las culturas que han existido a lo largo de la historia, a través de todos los recursos a nuestro alcance, adaptándose al público y al contexto, provocando la curiosidad y preguntas".

39 ID 17, respuesta 2: "La didáctica es enseñar y hacer comprender mediante diferentes métodos algo sobre lo que sabemos a otras personas para ponerlas en práctica".

40 ID 20, respuesta 2: "Sensibilizar, enseñar, aleccionar". 
- Pasado para el presente y el futuro: uno de los participantes expresó que la finalidad de la didáctica era "Conocer el pasado, entender el presente y preservar en el futuro" (ID 3, respuesta 2). A diferencia de otras respuestas, en las que la finalidad era transmitir un conocimiento o comprender un contenido, esta persona puso en relación una escala temporal (pasado, presente y futuro) con una cadena de acciones, también relacionadas (conocer, comprender y preservar). En este caso, se trata de una perspectiva desde el receptor.

\section{Discusión de resultados: la didáctica de la arqueología y su función según los participantes y según la teoría}

La didáctica de la arqueología se nutre de dos disciplinas plenamente definidas y diferencias: la arqueología y la educación. Esto implica que, en una disciplina relativamente joven como la didáctica de la arqueología, se deban unir dos campos con una larga trayectoria investigadora ${ }^{41}$. El campo de la educación en arqueología es comunicación entre arqueólogos y público, pero, a diferencia de otras acciones de difusión o divulgación, tiene como objetivo primordial provocar un aprendizaje (más o menos explícito) en el destinatario ${ }^{42}$. Con ello, incluimos en didáctica de la arqueología no solo las acciones destinadas a público escolar, sino también aquellas que, destinadas a un público más amplio, tienen también un claro objetivo de aprendizaje: así, la museografía puede resultar didáctica ${ }^{43}$, pero también los programas de televisión u otras formas de comunicación ${ }^{44}$, además de las actividades educativas en museos, escuelas, centros educativos... A diferencia, pues, de otras acciones comunicativas y de difusión y divulgación en arqueología, la didáctica se basa en la relación entre docente o emisor, un discente o destinatario, y unos contenidos que, en base a unos objetivos, en un contexto concreto, y mediante estrategias, recursos y metodologías determinados, producen un aprendizaje ${ }^{45}$. La didáctica, así, es una disciplina, un conjunto de estrategias para la enseñanza y el aprendizaje y, de este modo, se relaciona con la educación.

41 S. J. SMITH y K. SMARDZ: "Introduction". En K. Smardz y S. J. Smith (eds.): The Archaeology Education Handbook. Sharing the Past with Kids. Altamira Press, Walnut Creek: 2000. Páginas 25-38. 42 G. CARDONA-GÓMEZ: "Pero... ¿de verdad esto es importante? La didáctica de la arqueología desde la academia y la investigación". La Linde, 4 (2015), páginas 83-100.

43 J. SANTACANA-MESTRE: "Museografía didáctica, museos y centros de interpretación del patrimonio histórico". En J. Santacana y N. Serrat (coords). Museografía didáctica. Ariel, Barcelona: 2005. Páginas 63-101.

44 M. CORBISHLEY: Pinning Down the Past. Archaeology, Heritage, and Education Today. The Boydell Press, Woodbridge: 2011.

45 Uno de los autores que explica el modelo del triángulo didáctico o pedagógico es J. HOUSSAYE: Le triangle pédagogique. Peter Lang, Berna: 1988. 
En general, alrededor de la didáctica de la arqueología podríamos considerar dos enfoques principales. El primero considera que la didáctica de la arqueología es equivalente a la educación patrimonial aplicada al ámbito arqueológico, es decir, al diseño, realización y evaluación de actividades educativas para el ámbito educativo formal (escuelas, institutos, etc.) y no formal (museos, yacimientos, etc.), principalmente para público escolar ${ }^{46}$. Se centra en el ámbito tradicional de la didáctica y la educación, entendidas como acciones propias de la enseñanza reglada y ámbitos relacionados.

La segunda concepción entiende que la didáctica implica una forma de diseñar, realizar y evaluar acciones que, de forma más o menos explícita, permitan un aprendizaje efectivo en el usuario. La didáctica puede aplicarse, según esta visión, también en los ámbitos de la difusión, la interpretación patrimonial, la divulgación y la comunicación científica. Un programa televisivo puede ser parte del ámbito de la didáctica de la arqueología si tiene una vocación educativa y transformadora, si respeta las características propias de emisor, receptor y contenidos (mensaje) y los pone en relación de forma que se permita un aprendizaje efectivo. Se incluyen, pues, todas las acciones de los ámbitos educativos formal (escolar), no formal (museos, ámbito de ocio educativo) e informal (medios de comunicación, cursos para adultos, conferencias, etc. $)^{47}$.

Podríamos también analizar la didáctica de la arqueología y definirla en función del grado de implicación y participación de los destinatarios de la acción didáctica. En línea con los estudios de participación social en patrimonio arqueológico y ar-

46 Esta postura está defendida y presente en obras como las siguientes: T. COLE: Towards an assessment of the value of archaeological education for primary school pupils. Tesis doctoral inédita. University College of London, Londres: 2013. J. SANTACANA y F. X. HERNÀNDEZ CARDONA: Enseñanza de la arqueología y la prehistoria. Milenio, Lleida: 1999. K. SMARDZ y S. J. SMITH: The Archaeology Education Handbook. Sharing the Past with Kids. SAA - Altamira Press, Washington: 2000. Pp. 25-38. A. BARDAVIO y P. GONZÁLEZ MARCÉN: Objetos en el tiempo. Las fuentes materiales en la enseñanza de las ciencias sociales. Horsori - ICE, Barcelona: 2003.

47 Esta visión está presente en obras de autores como T. COPELAND que lo aplica a la interpretación patrimonial en "Presenting archaeology to the public: construncting insights on-site". En N. Merriman (ed). Public Archaeology. Routledge, New York: 2004. Pp. 132-144. Para ver este enfoque en ámbitos diversos en Reino Unido, véase D. HENSON y F. DAVIDSON: "The Council for British Archaeology and the Council for Scottish Archaeology". En D. Henson, P. Stone y M. Corbishley (eds): Education and the HIstoric Environment. Routledge, Londres: 2004. Pp. 79-88. Para el ámbito de los audiovisuales, véase la aportación de A. WEST "Archaeology and Television". En D. Henson, P. Stone y M. Corbishley (eds): Education and the Historic Environment. Routledge, Londres: 2004. Pp. 113-120. Para la aplicación de la didáctica en el campo de la museografía, véase J. SANTACANA y N. SERRAT (coords): Museografía didáctica. Barcelona, Ariel: 2005. Para una visión general de la didáctica de la arqueología y los ámbitos en que puede aplicarse, véase P. STONE: "Introduction. Education and the Historic Environment into the twenty-first Century". En D. Henson, P. Stone y M. Corbishley (eds): Education and the HIstoric Environment. Routledge, Londres: 2004. Pp. 1-12; y también la obra de M. CORBISHLEY: Pinning down the past. Archaeology, heritage and education today. Boydell Press, Woodbridge: 2011. 
queología pública, podríamos definir diferentes modelos de participación pública en arqueología, y también, en didáctica de la arqueología ${ }^{48}$. En la tabla 3, se pueden observar algunos de los modelos planteados por autores como Moussouri ${ }^{49}$, del campo de la comunicación científica; Pulido ${ }^{50}$, del campo de la socialización del patrimonio; Merriman ${ }^{51}$, Matsuda y Okamura ${ }^{52}$, del ámbito de la arqueología pública; y Henson ${ }^{53}$ y Hein ${ }^{54}$, de la educación en museos y en arqueología.

Como puede observarse en la tabla, los modelos propuestos por los diferentes autores permiten clasificar las posibles acciones realizadas en el campo de la arqueología y la socialización de su conocimiento desde distintas perspectivas. Los modelos más próximos a una participación pasiva de la sociedad implican que la academia, los profesionales de la arqueología o agentes similares tienen una posición de superioridad respecto al público destinatario, el cual no tiene casi posibilidad de participar en las acciones desarrolladas. Por ello, este tipo de acciones suelen utilizar estrategias dirigidas, expositivas, destinadas a difundir el conocimiento para que el público conozca, sepa más, sobre el pasado, pero sin permitirle una participación directa ni activa en la construcción del conocimiento.

Al otro extremo encontramos modelos que describen acciones y estrategias en los que no sólo se tiene en cuenta al público, sino que éste forma parte activa de las acciones de comunicación y socialización del patrimonio. Esto significa que los destinatarios no sólo realizan las acciones de socialización, sino que toman decisiones, toman parte activa en la creación de conocimiento y su difusión, integran el patrimonio arqueológico en su vida comunitaria, etc. Se tienen en cuenta distintas visiones y voces de la sociedad en la gestión y comunicación del patrimonio arqueológico, y se establece una relación horizontal entre arqueólogo o investigador, y público.

48 Para un mayor desarrollo y comparación entre modelos de participación en arqueología, ver G. CARDONA GÓMEZ: "Implicación social y patrimonio. Un cruce de caminos entre arqueología pública, arqueología comunitaria y didáctica de la arqueología". Arqueología y comunidad: el valor social del patrimonio arqueológico en el siglo XXI. Madrid, JAS Arqueología: 2016.

49 Véase T. MOUSSOURI: "From "Telling" to "Consulting": a Perspective on Museums and Modes of Public Engagement". En J. Lea y S. Thomas (eds.): Public Participation in Archaeology. The Boydell Press, Woodbridge: 2014. Pp. 11-22.

50 J. PULIDO: "La socialización del patrimonio: aclarando conceptos, centrifugando ideas". La Linde, 4 (2015), pp. 65-82.

51 N. MERRIMAN: "Introduction: diversity and dissonance in public archaeology". En N. Merriman (ed): Public Archaeology. Routledge, London: 2004. Pp. 1-17.

52 A. MATSUDA y K. OKAMURA: "Introduction: New Perspectives in Global Public Archaeology". En A. Matsuda y K. Okamura (eds.): New Perspectives in Global Public Archaeology. Springer, Londres: 2011. Pp. 1-18.

53 D. HENSON: "Does Archaeology Matter?" En G. Moshenska y S. Dhanjal (eds.): Community Archaeology. Themes, methods and practices. Oxbow books, Oxford: 2011. Pp. 120-127.

54 G. HEIN: Learning in the Museum. Routledge, New York: 1998. 


\begin{tabular}{|c|c|c|c|c|}
\hline & Pasivo & & & Activo \\
\hline Moussouri (2014) & Explicar & Compartir & Implicar & Consultar \\
\hline Pulido (2015) & Saber & Poder & Querer & Hacer \\
\hline Merriman (2004) & \multicolumn{2}{|c|}{ Deficit model } & \multicolumn{2}{|c|}{ Multiple perspectives model } \\
\hline $\begin{array}{l}\text { Matsuda y } \\
\text { Okamura (2012) }\end{array}$ & $\begin{array}{c}\text { Educational } \\
\text { approach }\end{array}$ & $\begin{array}{c}\text { Public relations } \\
\text { approach }\end{array}$ & Critical approach & $\begin{array}{l}\text { Multivocal } \\
\text { approach }\end{array}$ \\
\hline Henson (2011) & $\begin{array}{l}\text { Aprender sobre } \\
\text { el pasado }\end{array}$ & \multicolumn{2}{|c|}{ Aprender del pasado } & $\begin{array}{c}\text { Utilizar el } \\
\text { patrimonio del } \\
\text { pasado }\end{array}$ \\
\hline Hein (1998) & $\begin{array}{l}\text { Modelo } \\
\text { expositivo }\end{array}$ & $\begin{array}{c}\text { Modelo estímulo- } \\
\text { respuesta }\end{array}$ & $\begin{array}{l}\text { Aprendizaje por } \\
\text { descubrimiento }\end{array}$ & Constructivismo \\
\hline
\end{tabular}

Tabla 3. Gradación de modelos de relación arqueología - sociedad según el grado de participación activa de esta última, según distintos autores. Elaboración propia.

Si tenemos en cuenta los modelos expuestos, y los comparamos con las respuestas de los participantes del Cotarq en relación a cómo definirían la didáctica de la arqueología y qué acciones están relacionadas con ella, podríamos clasificar los enfoques teóricos según el grado de participación (o el grado en que se tiene en cuenta) al destinatario (figura 9).

Si tenemos en cuenta los distintos enfoques y en qué se basaban, podremos observar cómo, desde el punto de vista de la participación de los destinatarios, en general se trataría de visiones en que el público tendría una participación pasiva. Un análisis un poco más profundo de los enfoques en definir la didáctica nos muestra diferencias entre unos y otros, según si tienen más o menos en cuenta al destinatario y su aprendizaje. Por ello, hemos considerado al enfoque transmisivo como el más cercano a un modelo que pretende ofrecer y comunicar conocimientos al público, pero sin explicitar ninguna respuesta por parte de los destinatarios, ni tampoco observar su aprendizaje. A continuación encontraríamos el enfoque enseñanza, en el que nos acercamos a una perspectiva educativa, pero todavía nos encontramos en una perspectiva que da más importancia a la acción de transmitir conocimiento a la de aprender, comprender y participar de la construcción de este conocimiento por parte del destinatario. Esto dos enfoques son los más recurrentes en las respuestas a la primera pregunta por parte de los participantes.

A continuación se encontrarían aquellos enfoques que tienen en cuenta el aprendizaje del destinatario: el enfoque comprensivo y el enfoque de aprendizaje. En este contexto encontraríamos también al enfoque emocional. Los tres contemplan la transmisión y comunicación de contenido y conocimientos, pero van un paso más allá, explicitando la acción que debe afectar al destinatario: comprender, aprender, emocionarse. Por ello, y aunque no suponen necesariamente una mayor implicación y participación de los destinatarios ni tampoco explicitan 


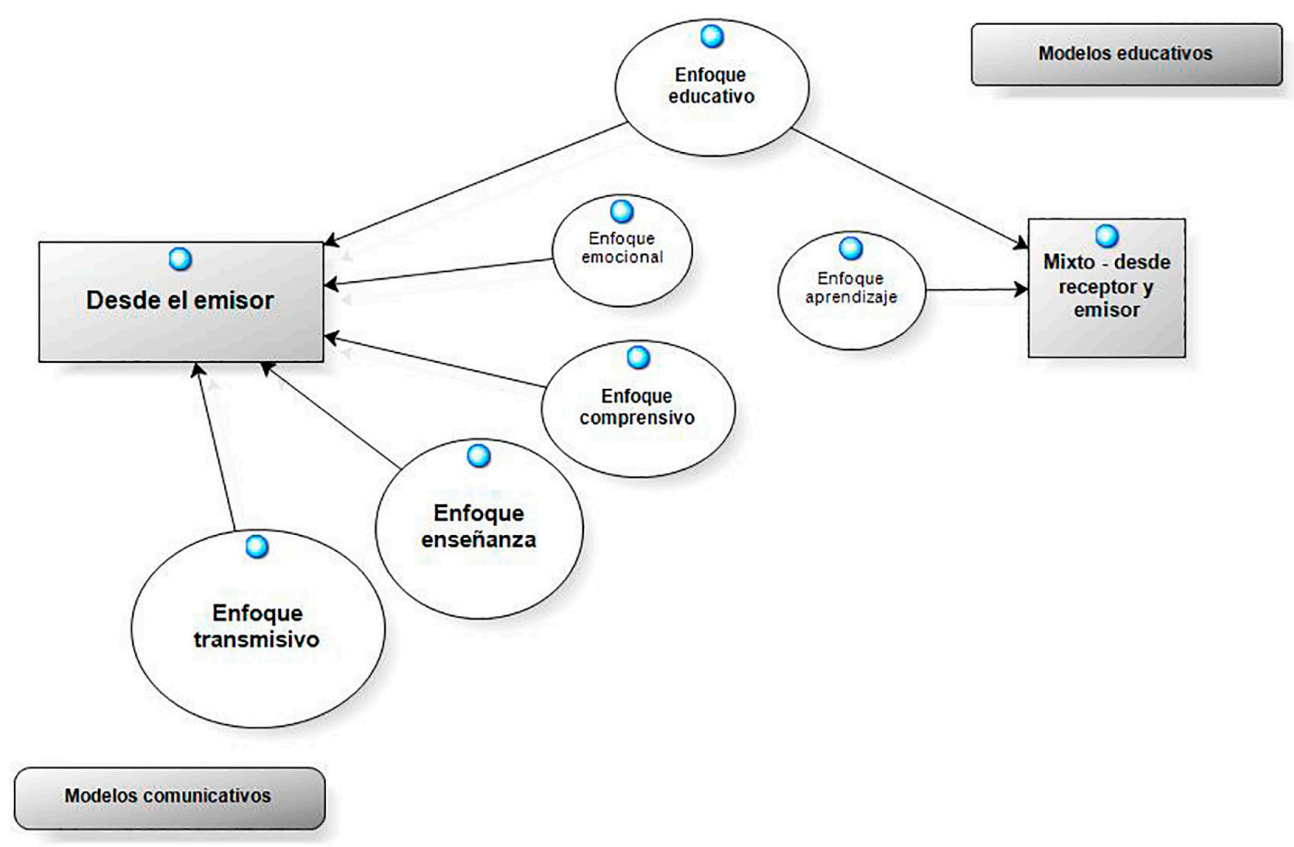

Figura 9. Modelo en que se muestran los enfoques según los cuales se ha definido la didáctica en las respuestas de los participantes en el Cotarq, ordenados en función de si se trata de una perspectiva más propia de la comunicación o de un enfoque educativo.

que el aprendizaje se construya de forma conjunta entre emisor y receptor, continuarían siendo modelos transmisivos, pero con mayor presencia del destinatario en su planteamiento.

Finalmente, hemos considerado que el enfoque educativo, aquél que tiene en cuenta no sólo el aprendizaje o la enseñanza, sino ambos, se situaría a continuación. Este enfoque presupone la interacción entre emisor y receptor, de forma que podría llegar a producirse algún tipo de participación activa del destinatario en la construcción del conocimiento y del aprendizaje.

Por lo que respecta a las finalidades u objetivos de la didáctica de la arqueología, desde la teoría podemos encontrar tres grandes enfoques generales. El primero de ellos considera que la didáctica de la arqueología tiene como finalidad dar a conocer, transmitir conocimientos sobre el pasado histórico, sobre la disciplina y profesión arqueológica y sobre el patrimonio cultural. Esta concepción de la finalidad última de la didáctica de la arqueología es más propia del siglo XX, en que la prioridad era la democratización del acceso y la comprensión de la cultura y del patrimonio ${ }^{55}$. A su vez, implica considerar el conocimiento histórico-arqueológico como científico, al presentar la arqueología como profesión y ámbito

55 F. X. HERNÀNDEZ CARDONA: "Museografía didáctica". En J. Santacana y N. Serrat (coords): Museografía didáctica. Ariel, Barcelona: 2005. Pp. 25-61. 
de investigación, y se relacionaría con una didáctica vinculada a la difusión, divulgación y comunicación de conocimientos históricos y sobre la arqueología.

Un segundo enfoque considera que la didáctica de la arqueología tiene como finalidad otorgar valor a las manifestaciones patrimoniales desde su conocimiento y respeto. En este sentido, la finalidad de la didáctica de la arqueología sería crear una cultura compartida ${ }^{56}$ que permitiera, por una parte, conocer y comprender el pasado, pero ir más allá: dotar de significado y valor al patrimonio cultural. Este enfoque implica ir más allá del conocimiento y la enseñanza de unos contenidos, sino que integra la comprensión, la educación en valores para la comprensión y respeto del patrimonio. La construcción de esta cultura compartida, de estos valores, permitiría, en última instancia, alcanzar la finalidad destacada en el siguiente enfoque.

El tercer enfoque destacado en cuanto a la finalidad de la didáctica de la arqueología defiende que su objetivo último es implicara la sociedad en la defensa y protección del patrimonio arqueológico desde el conocimiento, la comprensión, la valoración, el respeto y la acción. Esto implica, a su vez, diseñar intervenciones didácticas que permitan desarrollar la capacidad crítica del público, su creatividad, el planteamiento de cuestiones socialmente relevantes ${ }^{57}$ y la actuación social para proteger, salvar, conservar, etc. en el ámbito patrimonial. De esta forma, la didáctica de la arqueología permitiría salir más allá del ámbito propio de la disciplina (el conocimiento del pasado) para incidir en aspectos propios del presente y futuro de las comunidades, adquiriendo un sentido de formación ciudadana ${ }^{58} \mathrm{y}$ acción y participación comunitaria.

Henson, en esta línea ${ }^{59}$, propone un modelo de mediación entre patrimonio y sociedad que permita no solo difundir el conocimiento del pasado, sino una mayor participación social. Para ello, se podrían distinguir tres tipos de acciones: en primer lugar, el aprendizaje sobre el pasado - explorar y conocer lo que nos aporta la arqueología. La segunda, aprender del pasado, para comprender aspectos actuales, empatizar, comprender cambios, interacciones y continuidades y, así poder vincular pasado con presente: esta forma requiere una implicación cognitiva y emocional, especialmente si se realiza desde el diálogo entre agentes. Finalmente, propone la utilización del patrimonio para desarrollar identidades culturales, mostrar valores económicos y sociales, fomentar la acción comunitaria y el sentimiento de pertenencia a un lugar. La propuesta de Henson interrelacionaría las tres concepciones relativas a la finalidad de la didáctica de la arqueología.

56 P. GONZÁLEZ MARCÉN: "La dimensión educativa de la arqueología". Ponencia en La tutela del patrimonio prehistórico. Congreso memorial Siret, 22-25 septiembre 2010. Antequera.

\section{7 idem.}

58 T. COPELAND: "Archaeological heritage education: citizenship from the ground up". Treballs d'Arqueologia, 15 (2009), pp. 9-20.

59 D. HENSON: "Does Archaeology Matter?" En G. Moshenska y S. Dhanjal (eds.): Community Archaeology. Themes, methods and practices. Oxbow books, Oxford: 2011. Pp. 120-127. 
Si volvemos a las respuestas de los participantes del Cotarq a la pregunta sobre la finalidad u objetivos de la didáctica, y los comparamos con los tres principales enfoques teóricos sobre el tema, podemos observar algunas tendencias. En primer lugar, debemos tener en cuenta que las respuestas a la pregunta son, en su mayoría, escuetas, con lo que es difícil, a veces, esclarecer su significado en profundidad. En segundo lugar, podemos ver cómo las respuestas más recurrentes se refieren a un modelo de didáctica enfocada a la transmisión y la enseñanza de conocimientos, es decir, relacionada con la primera perspectiva teórica expuesta. Las finalidades de transmitir conocimiento, enseñar y aprender y fomentar el conocimiento estarían en relación con este enfoque de tipo instructivo, divulgativo, encarado a la transmisión y adquisición de conocimientos sobre el pasado y la arqueología. Por otro lado, las respuestas relativas a una finalidad vinculada a la comprensión, provocar preguntas, la sensibilización y la aplicación práctica podrían vincularse al segundo enfoque, a aquel que considera que la didáctica de la arqueología tiene como finalidad la creación de una cultura compartida. Esto implica que el conocimiento va más allá para hacerse comprensible, conectado con realidades actuales, entre las cuales se encuentra el patrimonio. Podríamos considerar que la finalidad relacionada con el disfrute podría relacionarse con este enfoque, puesto que va un paso más allá respecto a la adquisición de conocimiento. Finalmente, la respuesta relacionada con la conexión entre pasado, presente y futuro ${ }^{60}$ se refiere al tercer enfoque, aunque sin una explicitación de ninguna acción concreta de protección del patrimonio ni participación activa del público destinatario. El conocimiento del pasado, la comprensión del presente y la preservación del patrimonio en el futuro se vinculan a la concepción defendida por Henson.

\section{A modo de conclusión. La educación y la didáctica... ¿importan en arqueología?}

Mike Corbishley afirmaba que "Archaeologists need to show the public, governments and teachers that archaeology matters" ${ }^{\prime 61}$. Es importante para la educación patrimonial y la didáctica de la arqueología, en nuestro caso, que transmitamos los conocimientos propios de la disciplina y su campo de estudio; que comuniquemos y demos a conocer los beneficios, el potencial, la importancia del estudio, conservación y uso del patrimonio y la arqueología. De esto, en parte, depende la continuidad de la actividad profesional y académica, pero limitar la finalidad de comunicar qué es la arqueología y los conocimientos que genera a su propia supervivencia limita sus beneficios principalmente al colectivo de arqueólogos y arqueólogas. En cambio, si concebimos la comunicación desde nuestra

60 "Conocer el pasado, entender el presente y preservar en el futuro" (ID 3, respuesta 2).

61 M. CORBISHLEY, op. cit. p. 322. 
disciplina como una oportunidad de ofrecer espacios de participación social al público, su difusión y divulgación adquieren otra dimensión.

Además de dar a conocer la importancia de la arqueología a la sociedad, es necesario también que, desde la arqueología, demos importancia a las acciones de socialización del conocimiento. $Y$, entre estas acciones, se encuentra la educación y la didáctica patrimoniales. A lo largo del artículo hemos podido analizar las concepciones de algunos participantes del Cotarq sobre didáctica y su finalidad, en especial en el campo arqueológico, y se ha podido observar que, en general, las respuestas tienden a modelos dirigidos a transmitir conocimiento con una baja participación del público destinatario, aunque en algunos casos se incorpora parcialmente la visión del destinatario, y se da importancia al aprendizaje, la comprensión y la acción en lugar de la simple transmisión y recepción de conocimientos. El público asistente a la ponencia del Cotarq tenía, en principio, un interés en la didáctica de la arqueología y, por lo tanto, las concepciones recogidas son de personas que, vinculadas al ámbito arqueológico, tienen interés, relación o conocimientos sobre didáctica. Aun así, algunas concepciones sobre el ámbito de la educación en arqueología por parte de los participantes no apostaban por una visión constructivista del aprendizaje, por una concepción participativa de la didáctica patrimonial, ni tampoco se planteaban (en general) objetivos o finalidades más allá del "dar a conocer" la propia disciplina. Esto nos muestra que, todavía hoy, es necesaria una mejor formación y comunicación de las acciones y el campo de la didáctica de la arqueología a profesionales, colegas de profesión, investigadores e interesados en la temática. En otras ocasiones ${ }^{62}$ ya se han comentado las dificultades de la didáctica de la arqueología para ser (bien) considerada entre el colectivo de arqueólogos. Para empezar a cambiar esta dinámica, es necesaria más colaboración entre colectivos; más comunicación (también entre colegas) sobre qué acciones se desarrollan y su importancia; más formación en este campo; una mejor consideración desde la academia. Y, es por esto, que deberíamos cambiar un poco la afirmación de Corbishley: los arqueólogos debemos mostrar al público, los gobiernos y los profesores que la arqueología importa. Pero también debemos darnos cuenta que, sin la comunicación ni la educación, no podremos llegar a este público.

\section{Bibliografía}

A. BARDAVIO y P. GONZÁLEZ MARCÉN: Objetos en el tiempo. Las fuentes materiales en la enseñanza de las ciencias sociales. Horsori - ICE, Barcelona: 2003.

R. E. BOYATZIS: Transforming Qualitative Data: Thematic Analysis and Code Development. Sage, Thousand Oaks: 1998.

62 Vid nota 42. 
G. CARDONA GÓMEZ: "Implicación social y patrimonio. Un cruce de caminos entre arqueología pública, arqueología comunitaria y didáctica de la arqueología". Arqueología y comunidad: el valor social del patrimonio arqueológico en el siglo XXI. Madrid, JAS Arqueología: En prensa.

G. CARDONA-GÓMEZ: "Pero... ¿ ¿de verdad esto es importante? La didáctica de la arqueología desde la academia y la investigación”. La Linde, 4 (2015), páginas 83-100.

T. COLE: Towards an assessment of the value of archaeological education for primary school pupils. Tesis doctoral inédita. University College of London, Londres: 2013.

T. COPELAND: "Presenting archaeology to the public: construncting insights on-site". En N. Merriman (ed). Public Archaeology. Routledge, New York: 2004. Pp. 132-144.

T. COPELAND: "Archaeological heritage education: citizenship from the ground up". Treballs d'Arqueologia, 15 (2009), pp. 9-20.

M. CORBISHLEY: Pinning down the past. Archaeology, heritage and education today. Boydell Press, Woodbridge: 2011.

J. W. CRESWELL: Research Design Qualitative, Quantitative and Mixed Methods Approaches. Sage, Thousand Oaks: 2003.

P. GONZÁLEZ MARCÉN: "La dimensión educativa de la arqueología". Ponencia en La tutela del patrimonio prehistórico. Congreso memorial Siret, 22-25 septiembre 2010. Antequera.

G. HEIN: Learning in the Museum. Routledge, New York: 1998.

D. HENSON: "Does Archaeology Matter?" En G. Moshenska y S. Dhanjal (eds.): Community Archaeology. Themes, methods and practices. Oxbow books, Oxford: 2011. Pp. 120-127.

D. HENSON y F. DAVIDSON: "The Council for British Archaeology and the Council for Scottish Archaeology". En D. Henson, P. Stone y M. Corbishley (eds): Education and the Historic Environment. Routledge, Londres: 2004. Pp. 79-88.

F. X. HERNÀNDEZ CARDONA: "Museografía didáctica". En J. Santacana y N. Serrat (coords): Museografía didáctica. Ariel, Barcelona: 2005. Pp. 25-61.

J. HOUSSAYE: Le triangle pédagogique. Peter Lang, Berna: 1988.

A. MATSUDA y K. OKAMURA: "Introduction: New Perspectives in Global Public Archaeology". En A. Matsuda y K. Okamura (eds.): New Perspectives in Global Public Archaeology. Springer, Londres: 2011. Pp. 1-18.

N. MERRIMAN: "Introduction: diversity and dissonance in public archaeology". En N. Merriman (ed): Public Archaeology. Routledge, London: 2004. Pp. 1-17.

M B. MILES y A. M. HUBERMAN: Qualitative Data Analysis: An Expanded Sourcebook. Sage, Thousand Oaks: 1994. 
T. MOUSSOURI: "From "Telling" to "Consulting": a Perspective on Museums and Modes of Public Engagement". En J. Lea y S. Thomas (eds.): Public Participation in Archaeology. The Boydell Press, Woodbridge: 2014. Pp. 11-22.

J. PULIDO: "La socialización del patrimonio: aclarando conceptos, centrifugando ideas". La Linde, 4 (2015), pp. 65-82.

J. SANTACANA-MESTRE: "Museografía didáctica, museos y centros de interpretación del patrimonio histórico". En J. Santacana y N. Serrat (coords). Museografía didáctica. Ariel, Barcelona: 2005. Páginas 63-101.

J. SANTACANA y F. X. HERNÀNDEZ CARDONA: Enseñanza de la arqueología y la prehistoria. Milenio, Lleida: 1999.

J. SANTACANA y N. SERRAT (coords): Museografía didáctica. Barcelona, Ariel: 2005.

K. SMARDZ y S. J. SMITH: The Archaeology Education Handbook. Sharing the Past with Kids. SAA - Altamira Press, Washington: 2000. Pp. 25-38.

S. J. SMITH y K. SMARDZ: "Introduction". En K. Smardz y S. J. Smith (eds.): The Archaeology Education Handbook. Sharing the Past with Kids. Altamira Press, Walnut Creek: 2000. Pp. 25-38.

P. STONE: "Introduction. Education and the Historic Environment into the twenty-first Century". En D. Henson, P. Stone y M. Corbishley (eds): Education and the HIstoric Environment. Routledge, Londres: 2004. Pp. 1-12.

A. WEST "Archaeology and Television". En D. Henson, P. Stone y M. Corbishley (eds): Education and the Historic Environment. Routledge, Londres: 2004. Pp. 113-120. 
